\title{
Ultrasound-Guided Trigger Point Injections in the Cervicothoracic Musculature: A New and Unreported Technique
}

Kenneth P. Botwin, MD¹, Kavita Sharma, DO ${ }^{1}$, Romeo Saliba, MD¹, and Bharat C. Patel, MD²

From: Florida Spine Institute, Clearwater, FL; Deuk Spine Institute, Titusville, FL.

Dr. Botwin is Fellowship Director, Florida Spine Institute, Clearwater, FL. Dr. Sharma is with the division of Pain Management, Florida Spine Institute, Titusville, FL.

Dr. Saliba is with the Florida Spine Institute, Clearwater, FL. Dr. Patel is with the Deuk Spine Institute, Titusville, FL.

Address correspondence: Kenneth P. Botwin, MD, Florida Spine Institute 2250 Drew Street Clearwater FL 33765 E-mail: cbarragan@floridaspineinstitute. com

Disclaimer: There was no external funding in the preparation of this manuscript.

Conflict of interest: None.

Manuscript received: 07/03/2008 Revised manuscript received: 08/20/2008 Accepted for publication: 09/29/2008

Free full manuscript: www.painphysicianjournal.com
Background: Myofascial pain is defined as pain that originates from myofascial trigger points in skeletal muscle. It is prevalent in regional musculoskeletal pain syndromes, either alone or in combination with other pain generators. The myofascial pain syndrome is one of the largest groups of under diagnosed and under treated medical problems encountered in clinical practice. Trigger points are commonly seen in patients with myofascial pain which is responsible for localized pain in the affected muscles as well as referred pain patterns. Correct needle placement in a myofascial trigger point is vital to prevent complications and improve efficacy of the trigger point injection to help reduce or relieve myofascial pain. In obese patients, these injections may not reach the target tissue. In the cervicothoracic spine, a misguided or misplaced injection can result in a pneumothorax. Here, we describe an ultrasound-guided trigger point injection technique to avoid this potential pitfall. Office based ultrasound-guided injection techniques for musculoskeletal disorders have been described in the literature with regard to tendon, bursa, cystic, and joint pathologies. For the interventionalist, utilizing ultrasound yields multiple advantages technically and practically, including observation of needle placement in real-time, ability to perform dynamic studies, the possibility of diagnosing musculoskeletal pathologies, avoidance of radiation exposure, reduced overall cost, and portability of equipment within the office setting. To our knowledge, the use of ultrasound guidance in performing trigger point injection in the cervicothoracic area, particularly in obese patients, has not been previously reported.

Methods: A palpable trigger point in the cervicothoracic musculature was localized and marked by indenting the skin with the tip of a plastic needle cover. The skin was then sterile prepped. Then, using an ultrasound machine with sterile coupling gel and a sterile latex free transducer cover, the musculature in the cervicothoracic spine where the palpable trigger point was detected was visualized. Then utilizing direct live ultrasound guidance, a 25-gauge 1.5 inch needle connected to a $3 \mathrm{~mL}$ syringe was placed into the muscle at the exact location of the presumed trigger point. This guidance helps confirm needle placement in muscle tissue and not in an adipose tissue or any other non-musculature structure.

Results: The technique is simple to be performed by a pain management specialist who has ultrasound system training.

Conclusion: Ultrasound-guided trigger point injections may help confirm proper needle placement within the cervicothoracic musculature. The use of ultrasound-guided trigger point injections in the cervicothoracic musculature may also reduce the potential for a pneumothorax by an improperly placed injection.

Key words: Trigger point injection, myofascial pain, ultrasound

Pain Physician 2008; 11:6:885-889 


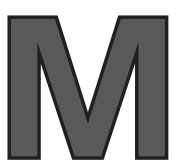

yofascial pain syndrome is one of many painful conditions of the musculoskeletal system. It constitutes some of the most important chronic problems encountered in a clinical practice (1). Myofascial pain is defined as pain that originates from myofascial trigger points in skeletal muscle. It is prevalent in regional musculoskeletal pain syndromes, either alone or in combination with other pain generators. The myofascial pain syndrome is one of the largest group of under-diagnosed and under-treated medical problems encountered in clinical practice. An appropriate evaluation and management of myofascial pain is an important part of musculoskeletal rehabilitation of regional axial and limb pain syndromes (2). A myofascial trigger point is a hyperirritable spot, usually within a taut band of skeletal muscle, which is painful on compression and can give rise to characteristic referred pain, motor dysfunction, and autonomic phenomena $(1,3)$. Trigger points have been proven causes of myofascial pain that are responsible for neck and back pain. Trigger points can be activated with local pressure or stretch of the tissue. They can also cause referred pain in a specific dermatomal and myotomal pattern. Trigger points may be relieved through noninvasive measures, such as spray and stretch, transcutaneous electrical stimulation, physical therapy, and massage. Invasive treatments for myofascial trigger points include injections with local anesthetics, corticosteroids or botulism toxin, or dry needling (1-6). Precise injections into the trigger points are vital in helping deactivate them.

Trigger points are usually palpated during physical examination before injecting them. It is very hard, and sometimes impossible, to palpate trigger points in the obese patients. At times, in these patients it is difficult to know if the needle is properly placed within the muscle tissue. This can perhaps lead to an increase in complications in these patients when performing trigger point injections in the posterolateral neck and thoracic spine musculature such as injection into the adipose tissue or pneumothorax.

A Medline/EMBASE review of literature did not reveal a description of this technique. Thus, this paper is the first to describe this new and previously unreported technique of trigger point injection utilizing ultrasound guidance in the cervicothoracic musculature. This report was approved by the institutional review board at the authors' institution.

\section{Methods}

After marking the trigger point injection site by indenting the skin with a plastic needle cover, the skin over that area is prepared by applying betadine and then alcohol. Then using an ultrasound system (Sonosite MicroMaxx compact ultrasound system [Fig. 1]) with sterile coupling gel and a sterile latex-free transducer cover, the musculature in the cervicothoracic spine where the palpable trigger point is detected was visualized. The region was scanned using at 13$6 \mathrm{MHz} 38 \mathrm{~mm}$ broadband linear array transducer. On ultrasound the skin appears hyperechoic, the adipose tissue is a mixed echogenicity and the muscle has a hyperechoic marbled appearance. Utilizing direct live ultrasound guidance a 25 -gauge 1.5 -inch needle connected to a $3 \mathrm{~mL}$ syringe is placed into the muscle at the exact location of the presumed trigger point longitudinal to the transducer. When in the color mode the injectate can be clearly visualized (Fig. 2).

The needle is seen to pass through the skin and adipose tissue and into the muscle. Needle placement in the specific muscle to be injected can be confirmed by asking the patient to activate that particular muscle while observing the musculature under ultrasound. Once the proper localization is achieved, the injection with or without an injectate can be performed. If an injectate with particulate corticosteroid is utilized it appears hyperechoic, while saline and anesthetics appear anechoic on ultrasound. At completion the needle is removed. Pressure is applied at the injection site to ensure proper homeostasis. A bandage can be applied.

\section{Discussion}

Trigger point injections have been proven to be useful to relieve myofascial pain in patients suffering from neck and low back pain (4-13). There are 2 possible problems when performing trigger point injections in obese patients. First, in such patients, it is difficult at times to determine whether the needle tip is in the muscle or in the adipose tissue. If the needle is not in the muscle, the injection will not relieve any pain and symptoms related to a trigger point. Secondly, trigger point injections in cervical and thoracic spine in all patients can be associated with the possibility of a pneumothorax (14-17). Electromyographic guidance has been recommended during a Botulinum toxin A injection for the treatment of muscle spasticity in post-stroke patients, cerebral palsy, and dystonia for 

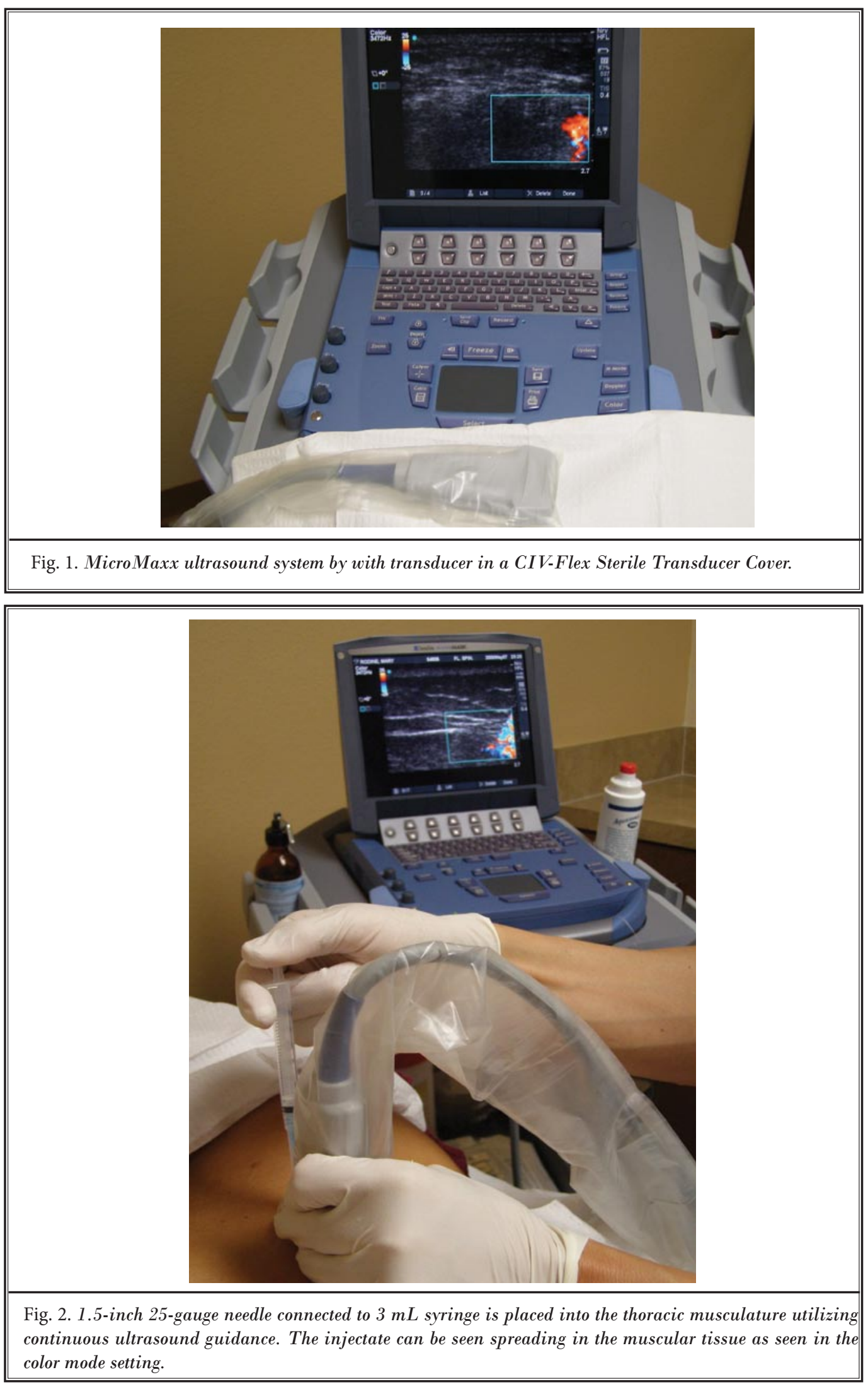
precise localization of a specific muscle as well as the motor point in that muscle by observing MUAPs and end-plate potentials before injecting (18-27). Botwin and Patel (28) described a similar technique with electromyographic guidance that can be useful when performing trigger point injection in the cervicothoracic regions in obese patients; however, the actual needle location cannot be visualized with this technique. A closed claims study found that trigger point injections are the second most common cause of pneumothorax ranking behind intercostal nerve blocks in $21 \%$ of cases (29). Trigger point injections can also be inadvertently placed intrathecally (17).

Ultrasonography has gathered momentum for widespread application in musculoskeletal medicine. Adler and Sofka (30) have demonstrated the role of musculoskeletal ultrasound in office-based percutaneous injections evaluating and treating disorders of joints, tendons, bursae, cystic pathologies, as well as injection of neuromas. Diagnostically, the utility of ultrasound may potentially be extended to include assessment of chronicity in sports-related injury (31). Smith et al (32) and Huerto et al (33) recently outlined a technique for ultrasound-guided injection of the piriformis muscle which could also be performed with additional motor stimulation for real-time reproduction of symptoms in patients with piriformis syndrome. Deep intraarticular injections, previously thought to require fluoroscopic guidance, have been successfully targeted using sonography (34). Aforementioned studies have all shown consistency when ultrasoundguided techniques were compared with conventional methods for procedures.

There are several technical considerations in performing ultrasound-guided injections. First, the addition of image guidance will likely result in increased time taken to perform office procedures. As well, the office setting must allow for enough space to comfortably manipulate the equipment and position the patient, taking into account any special physical limitations that the patient may have. The cost of ultrasound machines varies, however, this is still a consideration in most practice settings and is noted. Lastly, there are some limitations for the single operator stemming from the simultaneous use of image-guidance and performance of the injection, which may become less significant as the practitioner gains a comfort level with continued use of this equipment.

Clinical studies need to be done to evaluate the effectiveness of this technique compared with the conventional technique of trigger point injection without ultrasound guidance.

\section{Conclusion}

An ultrasound-guided trigger point injection technique helps confirm accurate needle placement in the cervicothoracic musculature. This could help to avoid injection into adipose tissue which may minimize the injection's effectiveness. The ultrasound guidance also could help to avoid the potential complication of a pneumothorax or inadvertent intrathecal injection. Thus, the use of ultrasund guidance may increase the efficacy of trigger point injections to reduce or relieve myofascial pain while reducing the possibility of complications.

\section{Medical Equipment}

MicroMaxx ultrasound system (SonoSite, Inc. Bothell, WA, USA)

Aquasonic 100 ultrasound transmission gel, water soluble (Parker Laboratories, Inc., Fairfield, NJ, USA)

CIV-Flex Sterile Transducer Cover (CIVCO, Kalona, IA, USA) 


\section{References}

1. Lavelle ED, Lavelle W, Smith HS. Myofascial trigger points. Med Clin North Am 2007; 91:229-239.

2. Borg-Stein J, Simons DG. Focused review: Myofascial pain. Arch Phys Med Rehabil. 2002 Mar; 83(3 Suppl 1):S407, S48-9. Review.

3. Simons DG, Mense S. Diagnosis and therapy of myofascial trigger points. Schmerz 2003 17:419-24. Review. German.

4. Simons DG, Travell JG. Myofascial origins of low back pain. Principles of diagnosis and treatment. Postgrad Med. 1983; 73:66, 68-70, 73.

5. Travell JG, Simond DG. Myofascial Pain and Dysfunction: The Trigger Point Manual: The Lower Extremities. Vol. 1. Baltimore, MD: Williams \& Wilkins, 1983.

6. Fischer AA. Local injections in pain management. Trigger point needling with infiltration and somatic blocks. Physical Med Rehabilitation Clinic North America, 1995:6:851-870.

7. Graboski CL, Gray DS, Burnham RS. Botulinum toxin $A$ versus bupivacaine trigger point injections for the treatment of myofascial pain syndrome: A randomized double blind cross over study. Pain 2005; 118:170-175.

8. Hamada H, Moriwaki K, Shiroyama K, Tanaka H, Kawamoto M, Yuge O. Myofascial pain in patients with post-thoracotomy pain syndrome. Reg Anesth Pain Med 2000; 25:302-305.

9. Staud R. Are tender point injections beneficial: The role of tonic nocieptor in fibromyalgia. Curr Pharm Des 2006; 12:23-27.

10. Borg-Stein J, Stein J. Trigger points and tender points: One and the same? Does injection treatment help? Rheum Dis Clin North Am 1996; 22:305-322.

11. Smith HS, Audette J, Royal MA. Botulinum toxin in pain management of soft tissue syndromes. Clin J Pain 2002; 18 (6 Suppl):S147-S154.

12. Hong CZ, Hsueh TC. Difference in pain relief after trigger point injections in myofascial pain patients with and without fibromyalgia. Arch Phys Med Rehabil 1996; 77:1161-1166.

13. Kamanli A, Kaya A, Ardicoglu O, Ozgoc men S, Zengin FO, Bayik Y. Comparison of lidocaine injection, botulinum toxin injection, and dry needling to trigger points in myofascial pain syndrome. Rheumatol Int 2005; 25:604-611. Epub 2004 Sep 15.

14. Simond DG, Travell JG, Simons LS. Travell and Simon's Myofascial Pain and Dysfunction: The Trigger Point Manual. 2nd Ed. Baltimore, MD: Williams \& Wilins, 1999:94-173.

15. Alvarez DJ, Rockwell PG. Trigger points: Diagnosis and management. Am Fam Physician 2002; 65:653-660.

16. Shafer N. Pneumothorax following "trigger point" injection. JAMA. 1970; 213:1193.

17. Nelson LS, Hoffman RS. Intrathecal in jection: Unusual complication of trigger-point injection therapy. Ann Emerg Med 1998; 32:506-508.

18. Klein AW, Mantell A. Electromyographic guidance in injecting botulinum toxin. Dermatol Surg 1998; 24:1184-1186

19. O'Brien CF. Injection techniques for botulinum toxin using electromyography and electrical stimulation. Muscle Nerve Suppl 1997; 6:S176-S178S10.

20. Childers MK. The importance of electromyographic guidance and electrical stimulation for injection of botulinum toxin. Phys Med Rehabil Clin N Am. 2003; 14:781-792.

21. Finsterer J, Fuchs I, Mamoli B. Automatic EMG-guided botulinum toxin treatment of spasticity. Clin Neuropharmacol 1997; 20:195-203

22. Molloy FM, Shill HA, Kaelin-Lang A, Karp BI. Accuracy of muscle localization without EMG: Implications for treatment of limb dystonia. Neurology 2002; 58:805-807.

23. Comella CL, Buchman AS, Tanner CM, Brown-Toms NC, Goetz CG. Botulinum toxin injection for spasmodic torticollis: Increased magnitude of benefit with electromyographic assistance. Neurology 1992; 42:878-882.

24. Barbano RL. Needle EMG guidance for injection of botulinum toxin. Needle EMG guidance is useful. Muscle Nerve 2001; 24:1567-1568.

5. Lang AM. Botulinum toxin type A thera- py in chronic pain disorders. Arch Phys Med Rehabil 2003; 84(3 Suppl 1):S69S73.

26. Lang AM. Botulinum toxin therapy for myofascial pain disorders. Curr Pain Headache Rep 2002; 6:355-360.

27. Lang AM. A preliminary comparison of the efficacy and tolerability of botulinum toxin serotypes $A$ and $B$ in the treatment of myofascial pain syndrome: A retrospective, open-label chart review. Clin Ther 2003; 25:22682278.

28. Botwin KP, Patel BC. Electromyographically guided trigger point injections in the cervicothoracic musculature of obese patients: A new and unreported technique. Pain Physician 2007; 10:753-756.

29. Kalawokalani D. Malpractice claims for non-operative pain management: A growing pain for anesthesiologists. ASA Professional Information, 1999.

30. Adler RS, Sofka CM. Percutaneous ultrasound-guided injections in the musculoskeletal system. Ultrasound Quarterly 2003; 19:3-12

31. Koh ESC, McNally EG. Ultrasound of skeletal muscle injury. Semin Musculoskeletal Radiology 2007; 11:162-173.

32. Smith J, Hurdle MF, Locketz AJ, Wisniewski SJ. Ultrasound-guided piriformis injection: Technique description and verification. Arch Phys Med Rehabil 2006; 87:1664-1667

33. Huerto APS, Yeo SN, Ho KY. Piriformis muscle injection using ultrasonography and motor stimulation - Report of technique. Pain Physician 2007; 10:687-690.

34. Smith J, Hurdle MB. Office-based ultrasound-guided intra-articular hip injection: Technique for physiatric practice. Arch Phys Med Rehabil 2006; 87:296298. 
